\title{
Prevalence of Staphylococcus aureus Isolated from Clinical Samples in a Tertiary Care Hospital: A Descriptive Cross-sectional Study
}

Jyotshna Sapkota, ${ }^{1}$ Manisha Sharma, ${ }^{1}$ Beena Jha, ${ }^{1}$ Chandra Prakash Bhatt ${ }^{1}$

'Department of Microbiology, Kathmandu Medical College and Teaching Hospital, Sinamangal, Kathmandu Nepal.

\section{ABSTRACT}

Introduction: Staphylococcus aureus is one of the commonest cause of nosocomial infections. Resistant Staphylococcus aureus strain has become a matter of concern. This study was done to find out the prevalence of Staphylococcus aureus from different clinical samples.

Methods: This descriptive cross-sectional study was carried out in the Clinical Microbiology laboratory from January 2019 to June 2019. Ethical approval was received from the Institutional Review Committee (Ref: 28122018010). Six hundred sixty-six sample size was calculated. Convenient sampling was done. Staphylococcus aureus was identified on the basis of its microscopy and morphological characteristics followed by catalase and coagulase test. Antibiotic sensitivity test of isolated pathogens was done using Muller Hinton Agar by Kirby-Bauer method. Statistical analysis was done by Excel 2018, point estimate at 95\% confidence interval was calculated along with frequency and proportion for binary data.

Results: Out of the 666 bacteria isolated from clinical specimens, 133 (19.96\%) were Staphylococcus aureus at $95 \%$ confidence interval (12.91-13.60\%). Seventy nine $(78.95 \%)$ of which is isolated from pus and wound infections. Out of 133 Staphylococcus aureus, 94 (70.64\%) were Methicillin-Resistant Staphylococcus aureus.

Conclusions: This study provides valuable information regarding the high prevalence of Staphylococcus aureus from pus and wound infections. The alarming number of Methicillin-Resistant Staphylococcus aureus is worrisome finding. Antibiotics like Vancomycin and Linezolid which has not developed resistance should be cautiously used only in Methicillin-Resistant Staphylococcus aureus cases.

Keywords: antibiotic resistance; MRSA; Staphylococcus aureus.

\section{INTRODUCTION}

Staphylococcus aureus, one of the most common causes of pyogenic infections is also a normal flora of the skin of human beings. ${ }^{1}$ It is a coagulase-positive, Gram-positive bacterium which is frequently implicated pathogen in bloodstream infections, skin and soft tissue infections, pneumonia, device-related infections and post-operative wound infections. ${ }^{2}$

A decrease in susceptibility of Staphylococcus aureus to beta-lactam antibiotics mainly penicillin and cephalosporin are reported worldwide. Various studies from different parts of the world show an increase in the number of Methicillin resistant Staphylococcus aureus (MRSA). According to data published by WHO in 2014, it showed greater than $80 \%$ of Staphylococcus aureus infections having MRSA. ${ }^{3}$ MRSA is one of the commonest causes of hospital-acquired infections

Correspondence: Dr. Jyotshna Sapkota, Department of Microbiology, Kathmandu Medical College Teaching Hospital, Sinamangal, Kathmandu, Nepal. Email: 21jyots@gmail.com, Phone: $+977-9851182704$ 
throughout the world. ${ }^{4}$

The aim of the study was to find out the prevalence of Staphylococcus aureus in our setting and antibiotic resistance pattern of isolated S.aureus.

\section{METHODS}

This descriptive cross-sectional study was carried out in the Clinical Microbiology Laboratory of Kathmandu Medical College and Teaching Hospital (KMCTH), Kathmandu, Nepal from the month of January 2019 to June 2019. Ethical approval was received from the Institutional Review Committee (Ref: 28122018010).

Convenient sampling was done and sample size was calculated using the formula,

$$
\begin{aligned}
\mathrm{n} & =\mathrm{Z}^{2} \times(\mathrm{p} \times \mathrm{q}) / \mathrm{e}^{2} \\
& =2.58^{2} \times 0.5 \times(1-0.5) / 0.05^{2} \\
& =666
\end{aligned}
$$

where,

$\mathrm{n}=$ required sample size

$p=$ prevalence of study $(50 \%)$

$q=1-p$

$\mathrm{e}=$ margin of error, $5 \%$

$\mathrm{Z}=2.58$ at $99 \% \mathrm{Cl}$

All the clinical specimens that were appropriately collected, labelled and properly transported and processed for aerobic bacterial cultures were included in this study. Six hundred sixty six culture-positive specimen isolates obtained from blood, urine, pus, wound swab, CVP tip, Eye swab, sputum, and tracheal were included in this study. Samples received were processed according to standard microbiological procedures. $^{5}$ Suspected colonies of $\mathrm{S}$. aureus were further processed. Identification of Staphylococcus aureus was done on the basis of colony character, Gram's staining, catalase test and coagulase test. ${ }^{6}$ Further Staphylococcus aureus was characterized into Methicillin sensitive Staphylococcus aureus (MSSA) and Methicillin-resistant Staphylococcus aureus (MRSA) by using cefoxitin disc diffusion method. Isolates with a diameter of zone of inhibition (ZOI) $\geq 22 \mathrm{~mm}$ were identified as MSSA and isolates with $\mathrm{ZOI} \leq 21 \mathrm{~mm}$ identified as MRSA. ${ }^{7}$ Antimicrobial susceptibility of all isolates was determined by the standard Kirby Bauer disk diffusion method according to norms of Clinical Laboratory Standards Institute (CSLI). Antibiotics included were Penicillin (P/10mcg), Cloxacillin, ciprofloxacin (CIP/5mcg), co-trimoxazole (COT/25mcg), cefoxitin (CX/30mcg), erythromycin (E/15mcg), clindamycin, cloxacillin, gentamicin (GEN/10mcg), vancomycin (VA/30mcg) and linezolid. ${ }^{8}$

\section{RESULTS}

The overall prevalence of S.aureus was 133 (19.96\%), with the prevalence of 470 (70.64\%) and 195 (29.32\%) of MRSA and MSSA respectively (Figure 1 ).

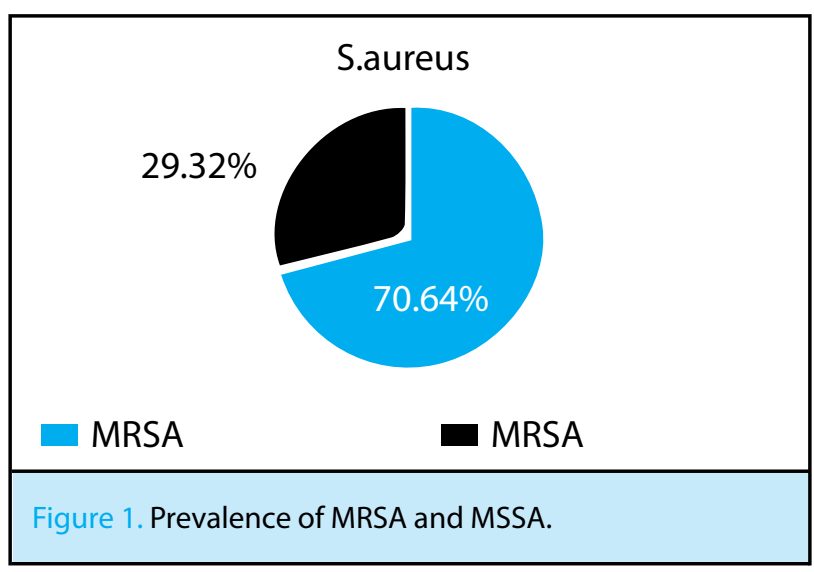

Staphylococcus aureus was isolated from various samples. Five hundred twenty-five $(78.95 \%)$ of the isolates were from pus and wound infections (Table 1).

\begin{tabular}{|lll|}
\hline \multicolumn{2}{|l|}{$\begin{array}{l}\text { Table } \\
\text { various }\end{array}$ clinical samples. } \\
\hline S.N & Clinical Sample & $\begin{array}{l}\text { Staphylococcus } \\
\text { aureus n (\%) }\end{array}$ \\
1 & Blood & $15(11.28 \%)$ \\
2 & CVP-tip & $3(2.26 \%)$ \\
3 & Eye swab & $1(0.75 \%)$ \\
4 & Pus & $49(55.64 \%)$ \\
5 & Sputum & $5(3.76 \%)$ \\
6 & Tracheal aspirate & $1(0.75 \%)$ \\
7 & Urine & $3(2.26 \%)$ \\
8 & Wound Swab & $31(23.31 \%)$ \\
\hline
\end{tabular}

The antibiogram of MRSA and MSSA shows that MRSA is resistant to most of the antibiotics as compared to MSSA (Table 2). 


\begin{tabular}{|c|c|c|c|c|c|c|c|}
\hline \multirow[b]{2}{*}{ S.No } & \multirow[b]{2}{*}{$\begin{array}{l}\text { Antibiotics } \\
\text { used }\end{array}$} & \multicolumn{3}{|c|}{ MRSA $(n=94)$} & \multicolumn{3}{|c|}{ MSSA $(n=39)$} \\
\hline & & $\begin{array}{l}\text { Resistant } \\
(\%)\end{array}$ & $\begin{array}{l}\text { Intermediate } \\
\text { Sensitivity } \\
\%)\end{array}$ & $\begin{array}{l}\text { Sensitive } \\
(\%)\end{array}$ & $\begin{array}{l}\text { Resistant } \\
(\%)\end{array}$ & $\begin{array}{l}\text { Intermediate } \\
\text { sensitivity (\%) }\end{array}$ & $\begin{array}{l}\text { Sensitive } \\
(\%)\end{array}$ \\
\hline 1 & Penicillin & 100 & & 0 & 66.67 & & 33.33 \\
\hline 2 & Cloxacillin & 37.23 & 0.75 & 61.7 & 7.69 & & 92.31 \\
\hline 3 & Ciprofloxacin & 47.87 & 0.75 & 51.06 & 15.38 & & 84.62 \\
\hline 4 & Gentamicin & 46.81 & & 53.19 & 15.38 & & 84.62 \\
\hline 5 & Cotrimoxazole & 42.55 & & 57.45 & 25.64 & & 74.36 \\
\hline 6 & Amikacin & 15.96 & & 84.04 & 0 & 0.75 & 97.44 \\
\hline 7 & Tetracycline & 34.04 & & 65.96 & 15.38 & & 84.62 \\
\hline 8 & Erythromycin & 78.72 & & 21.28 & 41.03 & & 58.97 \\
\hline 9 & Clindamycin & 35.11 & & 64.89 & 23.08 & & 76.92 \\
\hline 10 & Vancomycin & 0 & & 100 & 0 & & 100 \\
\hline 11 & Linezolid & 0 & & 100 & 0 & & 100 \\
\hline
\end{tabular}

\section{DISCUSSION}

S. aureus, one of the oldest pathogens known is still one of the commonest cause of pyogenic infections in humans. In this study, the prevalence of S.aureus among clinical isolates is $19.96 \%$, which is lower than the similar study done by Bhatt, et al. in 2011 which showed the prevalence of $30.4 \%$. But, our result is similar to the study conducted by Shahi, et al. in 2018 which shows the prevalence of $14.4 \%$ and other studies done globally also showed similar results. ${ }^{9-11}$

S.aureus is a normal flora of skin which can enter the body through cracks, abrasion, cuts, surgical incisions, burn and intravenous catheter and causes pyogenic infections. In our study, $78.95 \%$ isolates were from pus and wound swab samples indicating their key role in pyogenic soft tissue and wound infections. The higher frequency of $\mathrm{S}$. aureus isolation in pus samples compared to other samples has been reported in other studies in Nepal and other parts of the world. ${ }^{9-13}$

Among Gram-positive bacteria, S.aureus is known for resistance to various commonly used antibiotics. Antimicrobial resistance is a global threat and increasing drug resistance in S.aureus is worrisome. MRSA has emerged as an important human pathogen with a wide range of antibiotic resistance. Global scenario of MRSA is not uniform and great variation in its prevalence has been observed throughout the world. Earlier reports of MRSA from Nepal reported a prevalence of $21.1 \%$ $69.1 \% .^{11,14-16}$ Our result showed the prevalence of
MRSA as $70.64 \%$ which is alarmingly high as betalactam group of drugs are extensively used in our settings to treat bacterial infections. But this study is in accordance with data published by WHO in 2014. ${ }^{3}$ Proportionally high MRSA in our settings might have been due to differences in the length of the study period, study site, sample size, laboratory procedure employed and infection control practices. ${ }^{17}$ Equally likely is that the data reflects an actual increase in prevalence over the years as there is wide use of antibiotics available over the counter without specific laboratory tests in our country or it can also be transient local outbreak. . $^{18,19}$

We documented a higher prevalence of resistance to antibiotics in MRSA isolates when compared to MSSA isolates. All MRSA isolates encountered in this study were completely resistant $(100 \%)$ to penicillin. Similar results were noted for penicillin among MRSA strains in India. ${ }^{21} \mathrm{~A}$ significant difference in antibiotic resistance between MRSA and MSSA was observed in case of amikacin, ciprofloxacin, gentamycin and erythromycin which correlated with other studies from Nepal. ${ }^{11,14-16}$

Antibiotics like glycopeptides, linezolid should be judiciously used only in MRSA cases. Our study did not document any resistance to these antibiotics. Many studies in the past conducted in Nepal have also not documented any resistance to glycopeptides and linezolid. ${ }^{10,14-16}$ However, the study done by Pahadi et al. showed increased vancomycin MIC among MRSA. ${ }^{19}$ These antibiotics should be preserved for future use which will be most important in treating the MRSA 
cases.

Due to the limited resources the molecular study of the S. aureus isolates was not possible. The minimum inhibitory concentration (MIC) testing was also not possible.

\section{CONCLUSIONS}

The present study establishes $\mathrm{S}$. aureus as important pathogen to cause soft tissue and wound infections. With increase in prevalence of MRSA and VRSA we are headed to the pre-antibiotic era. Irrational use of antibiotics, absence of antimicrobial stewardship program in hospitals, lack of surveillance and reporting system, failure to observe infection control practices like hand washing and barrier nursing could be some reasons for this problem. Although no isolate exhibited resistance to vancomycin and linezolid screening test and MIC determination are recommended in monitoring the response to therapy and for early detection of impending resistance among local strains and these antibiotics should only be used in MRSA cases.

Conflict of Interest: None.

\section{REFERENCES}

1. Bennett JE, Dolin R, Blaser MJ. Mandell, Douglas, and Bennett's Principles and Practice of Infectious Diseases. 9th ed. Philadelphia: Churchill Livingstone; 2010; p. 2543-78. [Full Text]

2. Tong SYC, Davis JS, Eichenberger E, Holland TL, Fowler VG. Clin Microbiol Rev. May 2015;28(3):603-61. [라Med | Full Text | DOI]

3. World Health Organization. Antimicrobial Resistance: Global Report on Surveillance [Internet]. World Health Organization; April 2014 (cited 2019 Jun 15 ). [Full Text]

4. Lakhundi S, Zhang K. Methicillin-resistant Staphylococcus aureus: Molecular characterization, evolution, and epidemiology. Clin Microbiol Rev. Sept 2018;31(4):e00020-18. [ PubMed | Full Text | DOI]

5. Isenberg HD. Clinical Microbiology Procedures handbook. 2nd edition. Washington DC: ASM press; 2004. [Full Text]

6. Duguid J, Mackie, MacCartney. Staining Methods. Mackie \& McCartney practical medical microbiology. 14th ed. New York: Churchill Livingstone; 1996. p. 245-56. [Full Text]

7. Clinical and Laboratory Standards Institute, Performance Standards for Antimicrobial Susceptibility Testing. 26th ed. 950 West Valley Road, Suite 2500 Wayne, PA 19087 USA: 2016. 256 p. [Full Text]

8. Bhatt C, Karki B, Baral B, Gautam S, Shah A, Chaudhary A. Antibiotic susceptibility pattern of staphylococcus aureus and methicillin-resistant staphylococcus aureus in a tertiary care hospital. Journal of Pathology of Nepal. 2014;4(7):548-51. [Full Text | DOI]

9. Shahi K, Rijal K, Adhikari N, Shrestha U, Banjara M, Sharma V, Ghimire P. Methicillin Resistant Staphylococcus aureus: Prevalence and Antibiogram in Various Clinical Specimens at Alka Hospital. Tribhuvan University Journal of Microbiology. 2018;5:77-82. [Full Text | DOI]

10. Dilnessa T, Bitew A. Prevalence and antimicrobial susceptibility pattern of methicillin resistant Staphylococcus aureus isolated from clinical samples at Yekatit 12 Hospital
Medical College, Addis Ababa, Ethiopia. BMC Infect Dis. 2016 Aug 9;16(398):1742-5. [ubMed | Full Text | DOI]

11. Akpaka PE, Kissoon S, Swanston WH, Monteil M. Prevalence and antimicrobial susceptibility pattern of methicillin resistant Staphylococcus aureus isolates from Trinidad \& Tobago. Ann Clin Microbiol Antimicrob. 2006;5(16):1-6.

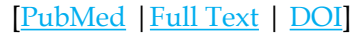

12. Pandey S, Raza MS, Bhatta CP. Prevalence and Antibiotic Sensitivity Pattern of Methicillin Resistant- Staphylococcus aureus in Kathmandu Medical College Teaching Hospital. Journal of Institute of Medicine. 2012 April; 34(1):13-7. [Full Text | DOI]

13. Khanal LK, Adhikari RP, Guragain A. Prevalence of Methicillin Resistant Staphylococcus Aureus and Antibiotic Susceptibility Pattern in a Tertiary Hospital in Nepal. J Nepal Health Res Counc. 2018 Apr-Jun;16(39):172-4. [PubMed | Full Text | DOI]

14. Raut S, Bajracharya K, Adhikari J, Pant SS, Adhikari B. Prevalence of methicillin resistant Staphylococcus aureus in Lumbini Medical College and Teaching Hospital, Palpa, Western Nepal. BMC Res Notes. 2017 Jun;10(1):187. [PubMed | Full Text | DOI]

15. Khanal LK, Jha BK. Prevalence of methicillin resistant Staphylococcus aureus (MRSA) among skin infection cases at a hospital in Chitwan, Nepal. Nepal Med Coll J. 2010;12(4):224-8. [PubMed]

16. Tiwari HK, Das AK, Sapkota D, Sivarajan K, Pahwa VK. Methicillin resistant Staphylococcus aureus: prevalence and antibiogram in a tertiary care hospital in western Nepal. Journal of Infection in Developing Countries. 2009;3(9):681-4. [PubMed | Full Text | DOI]

17. Mir BA, Srikanth. Prevalence and antimicrobial susceptibility of methicillin resistant Staphylococcus aureus and coagulase-negative Staphylococci in a tertiary care hospital. Asian J Pharm Clin Res. 2013;6(3):231-4. [Full Text]

18. Pahadi PC, Shrestha UT, Adhikari N, Shah PK, Amatya R. Growing resistance to vancomycin among methicillin 
resistant Staphylococcus aureus isolates from different clinical samples. J Nepal Med Assoc. 2014;52(196):977-81. [PubMed | Full Text $\mid \underline{\text { DOI] }}$
19. Chandrashekhar DK, Chandrakanth C, Sunilkumar B, Gangane R, Basavaraj P, VinodKumar CS, et al. Prevalence of methicillin-resistant Staphylococcus aureus in a tertiary care hospital in Gulbarga, Karnataka. J Pharm Biomed Sci. 2012;19(6):1-3. [FullText]

This work is licensed under a Creative Commons Attribution 4.0 International License. The images or other third party material in this article are included in the article's Creative Commons license, unless indicated otherwise in the credit line; if the material is not included under the Creative Commons license, users will need to obtain permission from the license holder to reproduce the material. To view a copy of this license, visit http://creativecommons.org/licenses/by/4.0/ 